\title{
RECONSTRUÇÂO HISTÓRICA DA UNIVERSIDADE ABERTA PARA A TERCEIRA IDADE NA UNIVERSIDADE ESTADUAL DE PONTA GROSSA
}

\author{
Rita de Cassia da Silva Oliveira ${ }^{1}$
}

\begin{abstract}
RESUMO
A educação é considerada pela Constituição Brasileira de 1988 um direito subjetivo de todo cidadão. Aliada a esta proposição, acrescenta-se o significativo envelhecimento populacional brasileiro. Não só o número de idosos tem-se ampliado, mas a longevidade Também se apresenta cada vez maior. Diante dessas questões, a educação para a pessoa idosa passa a ser considerada relevante, preconizada como educação permanente, na modalidade não formal, devem ser criados espaços educativos para a pessoa idosa nas diferentes universidades. O artigo objetiva refletir sobre a educação permanente; reconstruir historicamente a educação para o idoso, reconstruir a trajetória da criação e implantação da Universidade Aberta para a Terceira idade na Universidade Estadual de Ponta Grossa. Realizou-se uma pesquisa bibliográfica, documental, com um enfoque qualitativo e um estudo de caso. A educação propicia à pessoa idosa a aquisição de conhecimentos para instrumentalizá-los em uma participação mais ativa e integrada na sociedade, propiciando crescimento pessoal e intelectual.

Palavras-chave: Educação. Trajetória da Universidade Aberta. Políticas Públicas.
\end{abstract}

\section{RECONSTRUCTION OF HISTORICAL OPEN UNIVERSITY FOR THIRD AGE IN THE UNIVERSIDADE ESTADUAL DE PONTA GROSSA}

\begin{abstract}
Education is considered by the Brazilian Constitution of 1988 a subjective right of every citizen. Allied to this proposition, adds to the significant Brazilian population aging. Not only the number of elderly has increased, but longevity has also increased. Given these issues, education for the elderly shall be considered relevant, recommended as continuing education, in the form non-formal educational spaces must be created for the elderly in different universities. This article reflects on the continuing education; historically reconstruct education for the elderly, to reconstruct the history of the creation and implementation of the Open University for Third Age at the Universidade Estadual de Ponta Grossa. We conducted a bibliographical research with a qualitative approach and a case study. Education provides the elderly to acquire knowledge to instrumentalize them in a more active and integrated into society, providing intellectual and personal growth.
\end{abstract} Keywords: Education. Trajectory of the Open University. Public Policy.

\section{INTRODUÇÃO}

Refletir sobre a educação não é uma tarefa fácil, devido a complexidade que o fenômeno encerra, envolvendo muitos aspectos distintos e variáveis no tempo e espaço em que se situa. Pela própria origem etimológica da palavra educação, a contradição se faz presente, se por um aspecto significa alimentar, transmitir, por outro aspecto, desabrochar e transmitir. 
Para Pinto (1989), a educação é considerada um processo, um fato existencial e social. Além de ocorrer em sociedade, como fenômeno cultural não proporciona formação uniforme a todos os indivíduos porque é sustentada por uma ideologia, com finalidade estabelecida, inserida em um contexto sócio econômica, em um dado tempo histórico.

Em especial, a educação para a pessoa idosa embora reconhecida a relevância, existe ainda uma resistência com relação a temática, justificada pelos mais absurdos e inconsistentes argumentos como: não se tem retorno com esta faixa etária, deve-se investir em jovens...

Aliada a educação se constituir em um direito para todo indivíduo, acrescenta-se o grande contingente de idosos que compõe a população brasileira e que não podem ficar a deriva dos processos educacionais oferecidos em nosso país, considerando também a especificidade de metodologia, de conteúdos e de profissionais especializados para esta faixa etária.

As Instituições Escolares tornam-se um campo vasto de pesquisa histórica, uma vez que no seu interior ocorrem as maiores interações humanas: as relações sociais .

Estes locais se constituem em espaços onde são encontrados uma grande quantidade de fontes e informações que permitem a formulação de interpretações sobre elas próprias e sobre os seus sujeitos, o que é vital para o estudo da história da educação brasileira. Este novo procedimento de investigação em história da educação vem nos trazer a possibilidade de redirecionar nossa visão para o "[...] caminho de elaboração de interpretações sobre o passado educacional brasileiro em sua concretude, mediante consulta prévia a uma série enorme de fontes primárias e secundárias que não mais apenas a legislação educacional." ( GATTI JR , 2002)

Advém daí a necessidade da valorização das experiências educacionais que se dedicam a manter o ser humano ativo e o cidadão atuante, capaz de "[...] aprender a se desenvolver e a permanecer jovem e mentalmente vivo durante toda a vida, que vai muito além da vida produtiva exclusivamente dedicada a uma profissão." (CARVALHO, 2004)

Sendo a Universidade Aberta para a Terceira Idade uma Instituição que tem alcançado bons índices de aceitação de seus trabalhos, a sistematização de sua história tem sido mais um fator de valorização do idoso dentro da comunidade.

Foi realizada uma pesquisa bibliográfica, documental, de enfoque qualitativo que embasado na dialética permite reconhecer as causas, as contradições, as resistências, o contexto social no qual o objeto de estudo está inserido.

Desta maneira, aborda-se neste artigo a relevância da educação permanente e a educação não formal tendo como sujeito a pessoa idosa. Busca-se reconstruir e sistematizar a trajetória da história de criação e implantação da Universidade Aberta para a Terceira Idade na Universidade Estadual de Ponta Grossa, a qual completa 20 anos de existência, atendendo idosos da comunidade ponta-grossense e da região, destacando o seu trabalho inovador e responsável.

Como o crescimento demográfico acelerado se constitui uma tendência mundial, e também o envelhecimento da população e o número crescente de idosos significativamente se ampliando, busca-se superar a ideia de assistencialismo ou de infantilização da velhice pela valorização do idoso, em oferecer diferentes atividades educativas, em espaços das universidades para possibilitar uma melhoria na qualidade de vida, pela aquisição de conhecimentos, informações e maior participação social. 


\section{O panorama demográfico atual: o envelhecimento da população}

Um dos grandes desafios do nosso século é a longevidade humana. Aliada ao avanço nos anos de vida dos indivíduos, constata-se também o crescimento demográfico da população idosa, acima de 60 anos. Não se configura como uma tendência isolada, mas mundial que pode ser comprovada pelo Censo do Instituto Brasileiro de Geografia e Estatística (2008) no qual a população brasileira possui entorno de 21 milhões de idosos (15\%) e com perspectiva de no ano 2025 possuir cerca de 34 milhões de idosos. O Brasil será o sexto país com o maior número de idosos, o que acarretará uma mudança significativa no desenho demográfico do país.

O mundo tem presenciado uma mudança no perfil etário da população e, na América Latina, a população idosa atual atingiu a marca de 49 milhões de pessoas, representando cerca de $9 \%$ da população total. Para o ano de 2025 , a projeção é de 95 milhões de idosos, ou seja, $14 \%$ da população. Já no ano 2050, uma em cada quatro pessoas na América Latina será idosa, assim, essa população chegará a um crescimento de 85 milhões de idosos em relação a 2025, representando 24\% da população. (BATISTA et all, 2008; CAMARANO; PASINATO, 2007; ONU, 2006). Atualmente, há cerca de 688 milhões de idosos no mundo, isto significa que para cada grupo de 9 pessoas, há aproximadamente 1 pessoa com 60 anos ou mais (ONU, 2008).

No contexto global, a proporção de pessoas com 60 anos ou mais está crescendo mais rapidamente que a de qualquer outra faixa etária. Entre 1970 e 2025, espera-se um crescimento de $223 \%$ ou em torno de 694 milhões, no número de pessoas mais velhas (WHO, 2005, p. 8).

Os idosos mais velhos, aqueles com 80 anos ou mais, representam $13 \%$ da população idosa mundial. Em 2050, a proporção destes idosos será de $20 \%$ da população idosa. Atualmente, há cerca de 287 mil centenários. Em 2050, este número irá crescer consideravelmente, passando a marca de aproximadamente 3,7 milhões de centenários no mundo (ONU, 2008).

Segundo as projeções da ONU, em 2025, existirá um total de aproximadamente 1,2 bilhões de pessoa com mais de 60 anos no mundo e até 2050 haverá dois bilhões, sendo $80 \%$ nos países em desenvolvimento.

O envelhecimento da população é um fenômeno global que encerra grande complexidade pelos fatores que estão presentes e em decorrência traz importantes repercussões nos mais variados campos, entre os quais pode-se destacar o social e econômico.

Segundo Oliveira (1999, p.131)

Percebe-se que o envelhecimento populacional do Brasil ocorre em razão de alguns aspectos: aumento da expectativa de vida, diminuição da taxa de fecundidade, atribuída em grande parte aos avanços da medicina, e a busca de oferecer melhores condições de vida à população em termos de moradia, saneamento básico, alimentação, transporte, embora ainda exista muito o que fazer.

Este avanço e envelhecimento demográfico justificam e reclamam por mais estudos sobre as questões do envelhecimento e da velhice, considerando a complexidade e os diferentes aspectos que envolvem estas temáticas. Entretanto, ainda são incipientes as políticas públicas e em especial as educacionais voltadas a esta faixa etária.

A realidade vivenciada pelas pessoas idosas na sociedade capitalista pode ser considerada no mínimo cruel devido aos estigmas e preconceitos negativos cridos e 
cristalizados, impondo um culto a beleza e a juventude, aliada a produtividade e dinamismo, negando as pessoas idosas essas condições. A marginalização, as situações de violência que envolvem os idosos, também refletem esta realidade . Não raras vezes, os idosos são considerados sujeitos improdutivos e sem capacidade de aprender, considerados como um peso para a sociedade, obsoletos, ultrapassados, não lhes dando voz para apresentarem suas opiniões e posições.

Neste panorama que se torna necessária uma reconstrução do espaço educacional específico para a pessoa idosa, criado e implementado há algumas décadas em nível mundial e em especial no Brasil. Essa trajetória será abordada neste artigo, num primeiro momento na realidade macro, internacional e num segundo momento relativa ao espaço brasileiro, o estudo específico da Universidade Aberta para a Terceira Idade na Universidade Estadual de Ponta Grossa que possui atualmente 20 anos de existência com reconhecimento acadêmico e social.

\section{As primeiras experiências das Universidades da Terceira Idade: recuperando a história}

Sabe-se que as diferentes iniciativas educacionais são elaboradas conforme as necessidades e exigências da sociedade. Assim, as representações sociais atribuídas à velhice em meados dos séculos XIX, significavam um rompimento das atividades laborais, implicando em uma mudança no estilo de vida e de costumes e, em decorrência, um distanciamento e isolamento social, o idoso volta-se mais para a família, reduzindo sua participação social e seu grupo de convivência, gerando um clima desalentador para a velhice.

Entretanto, os idosos que nasceram nas primeiras décadas do século XX vivenciaram uma realidade um pouco distinta daquela vivida por seus pais, na qual se pode registar a vida com satisfação depois da aposentadoria. Neste contexto, no qual as pessoas idosas tiveram maior visibilidade social, iniciou-se, embora lento, preocupações teóricas e práticas voltadas a esta faixa etária que variam desde oferecer melhores condições de vida, turismo, programas educacionais, políticas voltadas à pessoa idosa até a formação de profissionais para atender a esta faixa etária como também pesquisadores preocupados com esta temática.

Ao levantar o aspecto histórico percebe-se que ainda é muito recente o interesse por esta fase da vida que, somente em 1962 recebe a designação de "terceira idade".

Este termo foi proposto por Huet na revista Informations Sociales, que dedicava este número específico aos aposentados.

Os Estados Unidos e a França são os primeiros países a oportunizarem um espaço educacional para idosos. Tais experiências educacionais remontam a 1970 e refletem a preocupação com o envelhecimento populacional de ambos os países.

Nos EUA a primeira experiência educacional para idosos aconteceu no século XVIII, tendo como princípio educativo o desenvolvimento da cidadania. Segundo Cachiori (1999, apud NERI, 1999, p.142), a educação religiosa assumiu uma orientação política e cívica à medida que "a capacidade para ler e escrever era desenvolvida para que todos os indivíduos adultos pudessem participar das decisões da nação e recebessem orientações religiosas, através da leitura e do entendimento da Bíblia".

O presidente Benjamin Franklin (em 1727) foi um dos precursores na criação de atividades educacionais para adultos e idosos nos Estados Unidos. Foi organizado um grupo denominado Junto, composto por adultos e idosos e durante trinta anos discutiram semanalmente questões relativas à sociedade. Já no século XIX, nasceu Luceum, com o objetivo de transmissão de conhecimentos para habitantes de municípios rurais. Consistia 
em um programa educacional para adultos e para idosos. Concomitante foi criado o Chautauqua voltado para desenvolver atividades artísticas, tendo a música e o teatro como as principais atividades desenvolvidas nos espaços de diversas igrejas (CACHIONI, 2003).

$\mathrm{Na}$ década de 1950, a Universidade de Chicago e a Universidade de Michigan preocupadas com o envelhecimento da população, ofereceram cursos de preparação para a aposentadoria e nas décadas seguintes foram criados programas de treinamento para o trabalhador idoso, expandido também as pesquisas e produções científicas na área da gerontologia, difundindo sensivelmente os conhecimentos nesta área.

A primeira experiência registrada na área de educação foi criada na França, em 1960, chamada de Universidades de Tempo Livre, as quais são consideradas precursoras das Universidade da Terceira Idade, com o objetivo primeiro de preencher o tempo livre das pessoas idosas e aposentadas, oferecendo diferentes atividades culturais e lúdicas.

Também foi na França que em 1973, Pierre Vellas fundou a primeira Université du Troisième Âge (UTA) e segundo o próprio criador objetivava uma maior participação do idoso, incentivo à sociabilidade, gosto de pela vida e com isto a busca de uma mudança na representação social que sociedade atribuía à velhice.

Segundo Palma (2000, p.53),

As dificuldades geradas pela idade podem ser compensadas através de novas possibilidades em um programa de vida social, atividades físicas, culturais e da medicina preventiva. Em síntese, a UTA foi criada para:

a) promover o protagonismo das pessoas idosas na tomada de decisões sobre seus problemas coletivos e pessoais, assim como lhes oferecer alternativas que melhores sua qualidade de vida;

b) colocar infra-estruturas e ambientes universitários a serviço do coletivo que era e ainda é chamado de terceira idade para diminuir sua marginalização, dando-lhes maior participação na vida social sem discriminação pelos seus muitos anos;

c) aprofundar as pesquisas gerontológicas e, tarefas interdisciplinares nas quais participem os idosos como investigadores e como investigados.

As UTAs ofereciam um programa educacional às pessoas idosas, visavam possibilitar uma maior inserção e preparação dos idosos para que se "(re)insiram na sociedade e, se necessário, intervenham em seus problemas” (PALMA, 2000,p.53).

Outro ponto relevante volta-se para a importância dada à pesquisa, visando avanços na qualidade de vida dos idosos de modo geral, não apenas dos alunos das UATs.

Como tentativa de superar a discriminação e marginalização que as pessoas idosas sofriam, e pode-se ver que ainda sofrem, preocupou-se com o esboço de uma nova imagem da pessoa idosa, estimulando os idosos a desenvolverem atitudes de participação na vida social, econômica. política e cultural, e concomitantemente, também possibilitar um maior relacionamento entre as gerações.

O espaço criado para os idosos nas universidades proporcionavam atividades ocupacionais e lúdicas, porém, ofereciam condições para o autodesenvolvimento e atualização, através de um espaço de compartilhamento de experiências acumulada pelos idosos, saberes, permitindo a reflexão entre os pares na busca de rupturas de estigmas e estereótipos negativos, sem fundamentação científica, em detrimento de um novo idosos, mais participativo e inserido socialmente, diminuindo o impacto ocasionado pelo envelhecimento e as mudanças rápidas que aconteciam em todas as sociedades.

As Universidades Abertas a Terceira Idade foram se disseminando pela Europa e América. 
Com a evolução da UTAs, em 1980, com um perfil diferenciado dos alunos, com maior escolaridade, segundo Palma (2000, p.58)

Três eram os eixos que fundamentavam a programação dessas UTAs: participação, autonomia e integração. Os participantes deixavam a posição de simples consumidores para serem produtores de conhecimento na medida em que participam das pesquisas universitárias.

Os alunos passaram a desenvolver um papel ativo nas pesquisas universitárias.

Basicamente podem ser considerados dois modelos de universidades para a terceira idade: o francês e o inglês, relacionando-os com os dois países considerados precursores nas ofertas educativas para os idosos.

O modelo francês, segundo afirma Pacheco (2003, p.223-224)

[...] tem suas bases no sistema tradicional universitário daquele país e privilegia o segmento mais velho da população sem, contudo, se fechar às outras faixas etárias preocupadas com o envelhecimento ou em busca de oportunidades de educação continuada. Os cursos, as oficinas de trabalho, os grupos de estudo e outras modalidades oferecidas são diversificadas e abertos, compostos de conteúdos e metodologias próprias, centradas no modelo da educação continuada daquele país. Soma-se a eles o acesso aberto e disponível a diferentes cursos universitários, especialmente nas páreas de ciências humanas e artes.

Este programa, também chamado de modelo Vellas, atende os idosos, aposentados, donas de casa, desempregados. A terminologia sofreu modificações conforme o programa variando entre Universidades do tempo Livre, Universidade para o Lazer ou Universidade de meia Idade.

Este modelo são encontrados na Itália, Portugal e Bélgica e possuem como objetivos a "atualização cultural, instrumentalização do idoso, visão crítica da velhice, desenvolvimento de ações e pesquisas que incluam ajuda mútua e organização das atividades de interesse popular" (FLORENZANO, 1991 e SWINDELL e THOMPSON, 1995 apud CACHIONI, 1998).

Outro modelo conhecido é o modelo inglês.

$\mathrm{O}$ modelo inglês oferece possibilidade dos alunos se engajarem em pesquisas, atuando como professores e como alunos. Busca um compartilhamento de saberes e experiências intergeracionais, baseia-se na auto- ajuda partindo da ideia de que todos os profissionais irão envelhecer.

Conforme afirma Pacheco (2003, p.224)

O modelo inglês nasceu em Cambridge, em 1981, baseando-se no ideal da auto-ajuda. A certeza de que tosos os especialistas de todas as áreas envelhecem e se aposentam norteou a criação de um espaço de troca, dentro das universidades, entre os mais velhos e os mais jovens. Essa interação de conhecimentos das pessoas envolvidas no projeto aumentaria as relações interpessoais, através do contato com seus semelhantes, e levaria a uma ação integrada dos profissionais mais velhos e dos mais jovens. Seria esperado, a partir dessa integração, o desenvolvimento de projetos comuns com a colaboração profissional , a integração com a universidade, com a sociedade. Essa experiência criará oportunidades aos 
participantes para manutenção da sua competência e do sentimento de autovalorização de forma mais prolongada e constante.

Esses dois modelos foram se disseminando por todo o mundo, inclusive no Brasil, sofrendo modificações conforme as necessidades locais, mas tendo como princípio maior, oferecer um espaço educativo, oportunizando o enriquecimento cognitivo, integração de conhecimentos, relacionamento intergeracional, elevação da auto estima e valorização da pessoa idosa.

\section{As Universidades Abertas na sociedade brasileira: uma realidade}

As Universidades Abertas para a Terceira Idade (UATI) tem sido criadas nas diferentes universidades pelo mundo como uma modalidade da educação não-formal e educação permanente ao mesmo tempo que instrumentaliza o idoso com conhecimentos, informações, possibilitando e legitimando o exercício pleno da cidadania.

Estas UATIs caracterizam-se pelo encontro de gerações, a não-obrigatoriedade de frequência, a ocorrência de ações e experiências em espaços e tempos mais flexíveis, não restritos aos fixados por órgãos reguladores.

A educação não-formal, ao contrário da educação formal, caracteriza-se por não ter a preocupação de desenvolver um currículo pré-definido, um currículo que se faz principalmente baseado em desejos, necessidades e interesses das pessoas que constituem os grupos envolvidos em ações e práticas desse campo educacional (SILVA, 2006, p. 9).

Segundo Gohn (2006) a educação não-formal representa várias dimensões, como a aprendizagem dos direitos numa perspectiva política, desenvolvimento de potencialidades, exercício de práticas comunitárias e sociais, aprendizagem que capacite para uma leitura de mundo, transmissão de informações, como também a formação política, social e cultural. A educação não-formal acontece em compartilhamento de experiências, em espaços e ações coletivas e cotidianas.

Nesta perspectiva da educação não-formal, as UATI buscam "oferecer possibilidades de experiências e vivências para que o público faça novas escolhas e opções pessoais e sociais [...]" (SILVA, 2006, p.9), além de oferecer conhecimentos, informações dentro de uma perspectiva de educação permanente.

Segundo Freire (1979, p. 27), "a educação é uma resposta da finitude da infinitude", pois o sujeito é incompleto, e encontra nos processos educacionais pressupostos para suprir sua constituição pessoal inacabada, independente de sua idade ou situação social.

Ao se pensar a educação como uma ação permanente e que o processo de aprendizagem ocorre durante toda a vida do homem, não evidencia apenas uma evolução do pensamento pedagógico, trata-se de uma necessidade de constante atualização num ambiente globalizado onde as mudanças são rápidas e contínuas, permitindo que o homem evolua segundo estes preceitos (OLIVEIRA, 1999).

Desta maneira, a educação enquanto prática social permite que o homem constantemente aprenda, tornando-se possível pensar numa transformação cultural e na própria sociedade. Para Pinto (1989, p. 39), "a educação não é uma conquista do indivíduo", mas sim "uma função da sociedade e como tal dependente de seu grau de desenvolvimento. Onde há sociedade há educação: logo, esta é permanente". 
A educação tem um papel político fundamental, (...) ela deve desempenhar um papel eminentemente democrático, ser um lugar de encontro, de permanente troca de experiências. (GADOTTI, 1984, p.157)

Percebe-se então que a educação possui um caráter de transformação, ultrapassando a mera ideia de transmissão de informações. Nesse sentido, parafraseando Piconez (2002), a educação instrumentaliza crítica e criativamente, tendo em vista a inovação da realidade. Desta maneira, observa-se o quanto o processo educativo permite um estágio de mudanças, independente da idade.

A evolução social decorre da ação educacional. Assim, a educação para a transformação implica num caráter permanente, tanto para que a sociedade possa se desenvolver, quanto para que o indivíduo possa estar integrado a este desenvolvimento.

O processo de aprendizagem não é exclusivo da instituição escolar, acontecendo nos mais diferentes espaços sociais. Segundo Gadotti (1984, p. 69), "a educação permanente visa uma educação rearranjada, refletida e integrada no seu todo. Ela sustenta a ideia de um controle de todos os recursos educativos possíveis de uma sociedade e de sua execução".

A educação ocorre ao longo da vida e não se limita a uma determinada idade. Toda educação pressupõe uma imagem de homem e de sociedade. Neste ritmo acelerado em que as sociedades atualmente se encontram, as mudanças são incontestáveis e surge a relevância de uma educação permanente, desenvolvendo habilidades, competências e buscando uma contínua aprendizagem, conhecimentos e atualização referente dos mais variados recursos tecnológicos que estão a serviço da sociedade.

Assim, "a preocupação básica que orienta o desdobramento de educação permanente e desenvolvimento cultural não se refere à contínua maturação humana, mas ao desenvolvimento socioeconômico e cultural" (PAIVA, 1985, p. 48). Possibilita-se, então, que o homem, no espaço histórico, cultural, político e social em que está inserido, consiga evoluir junto com a sociedade, e esta evolução individual reflete diretamente na constante evolução social.

"A educação é um processo contínuo e permanente que dá ao ser humano o sentido da vida, pela possibilidade que estabelece na medida em que promove maior compreensão sobre o mundo" (HERÉDIA, 2006, p. 126).

A educação permanente representa uma necessidade de ampliação da participação ativa do homem no contexto social e cultural, visando uma melhoria nas relações interpessoais, na qualidade de vida, na compreensão de mundo e na esperança de futuro melhor e mais digno. Pela educação permanente assume-se uma nova concepção de vida humana, cujo principio central é só aprender, mas principalmente viver para aprender, estando integrado e interagindo com quem se encontra ao seu redor (OLIVEIRA, 2007).

Quando se pensa em uma educação holística, necessariamente se reflete sobre uma educação que supere os processos discriminatórios, possibilitando uma educação contínua e relacionada com a prática social e o desenvolvimento do homem em sua totalidade.

Quando se pensa em educação ao longo da vida, subentende-se que o indivíduo aprende desde o nascimento até a sua morte, utilizando sua capacidade intelectual, constrói saberes, compartilha experiências e torna-se um contínuo aprendiz.

Segundo Moody (2008) é através da educação permanente que ocorre o desenvolvimento do capital humano, e esta educação deve acontecer independentemente da classe social ou nível de inserção/marginalização social do indivíduo, permitindo que o desenvolvimento intelectual, social, cultural e político ocorram.

Logo, numa perspectiva de educação permanente, torna-se imprescindível pensar esta para o idoso. Segundo Saraiva (2004, p. 31), o conceito de educação permanente, 
[...] como formulado originalmente, era uma crítica à ideia que separava em etapas ao longo da vida os períodos de formação (correspondentes à infância e a juventude), trabalho produtivo (idade adulta) e tempo livre (velhice, tempo posterior à aposentadoria), substituindo-se pela educação permanente, trazendo a ideia de contínua atualização de conhecimentos. Essa atualização é necessária frente ao ritmo acelerado da mudança social e tecnológica, além de diminuir o fosso cultural da terceira idade, já que, devido à redução dos índices de natalidade e elevação da expectativa de vida, a população tende ao envelhecimento.

Constata-se assim, a necessidade premente de ações educacionais para a educação do idoso, em caráter permanente.

Neste sentindo, a educação permanente é considerada como "um processo que não se conclui nunca, estendendo-se por toda a vida dos sujeitos. Significa dar oportunidade de aprendizagens contínuas, objetivando a atualização do ser humano, atendendo suas necessidades de interação e aprimoramento do saber" (TEODORO, 2006, p. 43).

Mosquera (1975, p. 141) conclui que "educação permanente é universal no seu caráter e essencial à completa democratização da aprendizagem, caracterizada pela sua flexibilidade e diversidade em conteúdos, apreendendo elementos, técnicas e finalidades abertas ao tempo e ao espaço".

Pela educação, os idosos serão instrumentalizados com conhecimentos permitindo que se organizem na consolidação de seus direitos, em busca de melhores condições e qualidade de vida.

Desta maneira, a educação assume o papel de propulsora da propulsora da transformação social, pois é através dela que além da aquisição de conhecimentos, o processo de socialização se intensifica, e a formação de um sujeito crítico e reflexivo se consolida.

Esta ideia espalha-se rapidamente pelo mundo e chega ao Brasil na década de 1980, período no qual a Universidade Estadual de Ponta Grossa desenvolve Seminários, Cursos e encontros na área de educação, destinados a pessoas idosas da comunidade.

\section{Primeiras iniciativas da educação do idoso no Brasil}

\section{Como afirmam Oliveira, Scortegagna e Oliveira (2011, p. 90),}

[...] tão fundamental quanto a cidadania, é o direito pela educação, pois não se alcançará a cidadania sem que haja conhecimento pleno deste direito. Logo, pensar a educação para a terceira idade é pensar mais que uma ocupação para o idoso, é permitir uma ação intensiva e intencional para que este sujeito se perceba, entenda seu entorno social, político e econômico, como também não seja ludibriado ou tenha seus direitos negligenciados.

A educação é considerada como um direito fundamental, que está incluso em algumas políticas públicas destinadas para as pessoas idosas, todavia ainda não existe nenhuma política que referencie exclusivamente a educação para esse público.

Nos anos 1980, surge a "Federação dos aposentados" que inicia em território nacional uma luta em favor de melhores condições aos aposentados, e, estes conseguem pequenas modificações e acréscimos a Constituição de 1988 , com a finalidade de garantir melhor assistência aos idosos.

Dentro da perspectiva de educação permanente e sendo a universidade um lugar por excelência para o aprimoramento, a pesquisa, a busca do conhecimento e também a 
democratização do saber, timidamente surge em seu âmago um espaço educacional para essa clientela. As universidades ampliam sua função social, "buscando integrar aqueles que se encontram à margem do processo de desenvolvimento" (OLIVEIRA, 1999).

Segundo Oliveira (1999) os primeiros grupos constituídos por idosos se formaram em 1960, como Grupos de Convivência, cujo projeto visava principalmente o lazer, sendo que o Serviço Social do Comércio (SESC) desde esta época já desenvolvia programas de atendimento não institucional a pessoas idosas. Seus cursos concentravam-se em artesanato, canto, ginástica, pintura e lazer em geral.

Em 1970, surgiram as escolas abertas para a terceira idade:

Projeto baseado nas experiências francesas, direcionado para um público mais qualificado em termos educacionais já que oferecia, em seus módulos, programas de preparação para a aposentadoria, informações sobre aspectos biopsicossociais do envelhecimento e atualização cultural, além das atividades físicas e complementação sóciocultutal. Esse programa sustenta-se numa proposta de Educação permanente e busca o desenvolvimento de potencialidades, de novos projetos de vida, estimulando a participação ativa do idoso e sua contribuição para a resolução de problemas em sua família e na comunidade (PALMA, 2000, p.71).

O pioneirismo do SESC não se limita a oferecer atividades para as pessoas com mais de cinquenta anos, mas também se volta para a formação de recursos humanos e ampliação do conhecimento gerontológico em eventos e cursos.

O envelhecimento humano passa a ser tratado na esfera política e transforma-se numa questão social e não mais numa questão puramente doméstica, porém ainda de forma tímida e insuficiente diante da demanda apresentada.

Dentro deste contexto surge a gerontologia como ciência que se encarrega de estudar o envelhecimento humano no aspecto social, sendo que no ano de 1961 é fundada a Sociedade Brasileira de Geriatria e Gerontologia, entidade que se dedicava "[...] aos debates sobre o estudo e o tratamento das enfermidades e transtornos da idade avançada". (LOPES, 2000).

A Gerontologia surgiu como uma exigência da própria sociedade, do envelhecimento populacional, a necessidade de uma investigação mais científica e sistemática para estudar o envelhecimento e a velhice, desenvolvendo métodos e técnicas adequadas para trabalhar com os problemas decorrentes desse segmento de maneira mais especializada e com mais profundidade.

Em 1914, Nascher, autor americano, lançou o livro Geriatrics - The diseases of old age and their treatment, considerado o ponto inicial da geriatria com bases modernas e uma abordagem mais ampla do assunto e estabelecendo também um marco do novo campo de conhecimento - a Gerontologia (JORDÃO NETTO, 1997).

A palavra gerontologia deriva de geronto, do grego velho e logia, estudo. Assim, constitui o estudo da velhice.

Trata-se de uma disciplina recente, do século XX, a qual surgiu como resultado de uma reflexão secular sobre o envelhecimento. Como campo de conhecimento, a Gerontologia deve ser considerada sob dois aspectos: por um lado como ciência e campo de investigação e por outro lado como educação e formação de recursos humanos para trabalharem com idosos.

No Brasil, surgem as primeiras iniciativas educativas voltadas ao idoso em diferentes instituições universitárias, voltadas para o ensino, saúde e lazer. 
Em 1982 foi fundado o Núcleo de Estudos da Terceira Idade na Universidade Federal de Santa Catarina que realizava estudos e divulgação de conhecimentos geronológicos, com a preocupação de formar recursos humanos e buscar uma maior visibilidade para o idoso na sociedade.

Na Universidade Federal de Santa Maria foi organizado em 1984 o Projeto Grupos de Atividades Físicas para a Terceira Idade, oferecendo diferentes atividades físicas para a pessoa idosa o que possibilita uma melhoria nas condições físicas e uma melhor qualidade de vida.

O Núcleo de Assistência ao Idoso foi criado no final da década de 1980 na Universidade Estadual do Rio de Janeiro, com a participação de profissionais de diferentes áreas de conhecimentos e posteriormente originou a Universidade Aberta à Terceira idade.

Entretanto, os projetos e cursos voltados a essa faixa etária no Brasil tiveram sua proliferação mais acentuada a partir de 1990, quando inúmeras universidades brasileiras abriram um espaço educativo para o idoso.

Entre as Universidades pode-se citar: A Pontifícia Universidade Católica de Campinas, em 1990, Universidade de Passo Fundo (RS), em 1991, Universidade Estadual de Ponta Grossa (PR), em 1992, Universidade Metodista de Piracicaba(SP), em 1992, Universidade de São Paulo, em 1995.

Embora com modelos e organização distintas, os cursos e projetos oferecidos pelas universidades brasileiras possuem o sujeito idoso como foco central das atividades e a valorização do idoso, melhoria da condição de cidadania e qualidade de vida como objetivo.

Essas diferentes iniciativas surgiram muito antes da sociedade política e civil perceber a necessidade da elaboração de politicas públicas voltadas para a pessoa idosa.

Data de 1994 a Lei 8.842 que instituiu a Política Nacional do Idoso e o Estatuto do Idoso, Lei 10.741, foi elaborado e promulgado em 2003.

Pode-se registar assim o pioneirismo também das universidades que constataram a mudança no perfil populacional brasileiro e suscetíveis a esse novo desenho demográfico elaboraram cursos e projetos para satisfazer a nova exigência social. Assim, dessa realidade emergiu a necessidade de programas alternativos que garantam maior qualidade de vida para esse segmento da população.

Embora exista a Lei 8842/94 que define a Política Nacional do Idoso, pouco foi feito efetivamente para a implementação da referida Lei.

O Estatuto do Idoso (Lei 10.741/03) prevê em seu capítulo V, artigo 20, ter o idoso o direito à educação, e, em seu artigo 21 rege que o Poder Público criará oportunidades de acesso do idoso à educação, adequando currículos, metodologias e material didático aos programas educacionais a ele destinados.

Esses artigos demonstram o reconhecimento da educação permanente como instrumento eficiente para a valorização e reconhecimento do idoso como um cidadão atuante, participativo e por isso merecedor de atendimento com qualidade.

Muitas assembleias foram realizadas, em nível mundial, voltados ao estudo do envelhecimento.

Entre as Assembleias, destaca-se a Assembleia Mundial sobre o Envelhecimento, a qual foi realizada em Viena, no ano de 1982. Desta assembleia resultou um plano internacional sobre envelhecimento, o qual foi considerado por muitos estudiosos o primeiro documento de nível mundial, o qual destacava a situação da população idosa e trouxe metas como atender às preocupações e necessidades especiais das pessoas de mais idade, e fomentar uma resposta internacional adequada aos problemas do envelhecimento, estabelecendo um nova ordem econômica e o desenvolvimento de atividades de 
cooperação técnica, principalmente entre os países em desenvolvimento (ONU, 1982). Desta Assembleia resultou o Plano de Viena.

A segunda Assembleia foi realizada em Madri em 2002, 20 anos após a primeira assembleia. Também resultou desta um plano internacional sobre o envelhecimento, conhecido como Plano de Madri. Nesta assembleia foi aprovado um outro documento, uma Declaração Política, na qual todos os países signatários comprometem-se em cumprir as metas do Plano de Madri em até 25 anos. O referido Plano traz três prioridades: necessidade das sociedades ajustarem suas políticas e instituições para que a crescente população idosa, promoção da saúde e bem-estar para todo o ciclo de vida e a criação de contextos propícios e favoráveis, que promovam políticas orientadas para a família e a comunidade como base para um envelhecimento seguro (MADRI, 2002).

A Conferência Mundial de Educação para Todos realizada em Dakar (2000), reafirmou a necessidade e a importância da educação em todas as idades. Recomendou-se novamente a necessidade de assegurar o direito de educação, para que haja a equidade de acesso a uma aprendizagem apropriada, que desenvolva habilidades e que possibilite programas de formação para a cidadania (ONU, 2000).

Percebe-se que existe um grande avanço com relação a preocupação da educação ao longo da vida, incluindo aqui a pessoa idosa.

\section{A reconstrução da trajetória da criação e implantação da Universidade Aberta para a Terceira idade na Universidade Estadual de Ponta Grossa}

Mesmo antes da sanção do Estatuto do Idoso, já no ano de 1992, a Universidade Estadual de Ponta Grossa, através da sua Universidade Aberta da Terceira Idade, tem trabalhado a fim de resgatar o idoso para o convívio e integração sociais através de uma atualização cultural e assim, valorizar o idoso e melhorar sua qualidade de vida a partir do momento em que contribui para que eles compartilhem seus sonhos, idéias e retomem a prática de construir projetos de vida, conquistando assim de volta uma posição importante no seio da família e da comunidade.

Ciente da "[...] necessidade de formulação e implementação de uma política de fontes" (SAVIANI, 2004) a coordenação da Universidade Aberta para a Terceira Idade se propôs a preservar sua história através do resgate e sistematização de suas fontes documentais e iconográficas, dentro de um projeto de pesquisa de história e memória da Instituição.

Considerando as funções das universidades: ensino, pesquisa e extensão, criou-se a Universidade Aberta para a Terceira Idade (UATI), em 1992, na Universidade Estadual de Ponta Grossa, através da portaria 212 de 01/08/91, abrindo espaço para os idosos, através de um projeto extensionista, articulando e aproximando-se da comunidade em que está inserida, a Universidade Estadual de Ponta Grossa cumpre sua função social em relação aos idosos, buscando superar a exclusão convencionada à idade, e , por conseguinte, leválos a usufruir os bens advindos com essa proposta.

Os diferentes programas oferecidos pelas universidades são formas alternativas de atendimento ao idoso, visando além da valorização dessa clientela, maior conscientização da sociedade em geral a respeito do processo de envelhecimento da população do nosso país que é uma realidade (BOTH, 2003).

$\mathrm{O}$ idosos a medida que participa das atividades promovidas pela universidade promove também a sua maior inserção acadêmica e social, além da integração de gerações, 
colocando em pauta nessa instituição questões relativas ao envelhecimento, a velhice, a discriminação, preconceitos que assombram o idoso deixando-os em condições de vulnerabilidade.

O próprio idoso, à medida que se conscientiza do seu papel social, de seu potencial como cidadão, se valoriza e contribui para esboçar um outro olhar da sociedade sobre esta faixa etária, estabelecendo um novo paradigma de velhice, na qual seus protagonistas são ativos, produtivos, integrados e valorizados.

O processo e criação da UATI foi árduo porque toda ideia inovadora certamente encontra resistências e por muitos é desconsiderado. $O$ trabalho exigiu também a sensibilização da própria comunidade para buscar apoio na implantação deste novo espaço educacional.

Iniciou-se com um grupo pequeno de colaboradoras que se dedicaram ao trabalho de planejamento e concretização da UATI.

Em conjunto com o departamento de Educação foi proposto de 1989 o I Encontro Vivencial da Terceira idade como uma primeira tentativa de colocar em pauta e ressaltar a reflexão sobre os problemas da pessoa idosa na comunidade.

A educação para o envelhecimento passou a ser preconizada dentro de condições sócio-econômicas e culturais, com seguridade social adequada, para a manutenção de uma vida digna e produtiva nessa faixa etária.

Partindo da premissa de que o importante é viver mais tempo, mas com qualidade, saúde física, mental e autonomia, embasou-se a ideia desse encontro, propondo uma reflexão sobre as estruturas sócio-culturais consolidadas, tendo como prerrogativa a criação de mecanismos de participação dos idosos na sociedade, visando alcançar, no futuro, a uma situação mais justa para todos.

Os objetivos do encontro arrolaram sobre a problemática do idoso na comunidade ponta-grossense, gerando discussões e reflexões sobre o tema, na tentativa de alertar e conscientizar a comunidade visando levantar alternativas para os problemas da pessoa idosa, favorecendo a integração e o congraçamento dos idosos.

O Encontro alcançou êxito em sua organização, mas não atingiu o número de participações desejadas porque ficou restrito a 30 idosos. A equipe de trabalho percebeu que muito ainda deveria ser feito para atrair mais idosos e mesmo os jovens acadêmicos ao redor desse projeto para que o sucesso realmente fosse alcançado.

No ano seguinte, em 1990, foi organizado o II Encontro Vivencial da Terceira idade - Trabalho e Lazer. O encontro teve como objetivos: proporcionar informações, atividades e lazer para a terceira díade da comunidade local, debatendo a problemática do trabalho e do lazer para o idoso em Ponta Gross; ao mesmo tempo, informando sobre o mercado de trabalho local oferecido na época, estimulando a participação e integração dos idosos em cursos e atividades que a comunidade para eles destina. O n'mero de participantes foi mais significativo, 50 pessoas, o que estimulou a organização do próximo evento com uma carga horária mais ampla que teve apenas 5 horas de duração.

Ao longo do ano de 1990, foram realizadas muitas visitas a Universidades brasileiras com a finalidade de angariar subsídios teóricos e metodológicos para a elaboração de um projeto consistente voltado para a pessoa idosa.

Foi de grande relevância a participação do Grupo de Trabalho da Terceira Idade (GTI) na organização do Projeto da Universidade Aberta para a Terceira Idade. Foram realizadas muitas reuniões destinadas a distintos segmentos da universidade com a intenção de promover e divulgar a ideia da criação e implantação da UATI, além de buscar apoio na comunidade universitária, também atrair adeptos a trabalharem no projeto extensionista que parecia estar no ápice de sua gestação. 
AS reuniões geraram certa polêmica e comentários ao redor do tema, mas também conseguiram apoio de diferentes pessoas que estimularam o avanço do GTI nessa caminhada.

No ano 1991 aconteceu o III Encontro Vivencial da terceira Idade - Integrando gerações. $\mathrm{O}$ encontro propunha refletir sobre o envelhecimento humano a partir dos enfoques social, político, cultural e espiritual, procurando, dessa forma, conscientizar a os estudantes, professores e participantes da questão do idoso enquanto responsabilidade coletiva e questionamento do próprio futuro.

Buscava, também, favorecer a integração entre gerações em uma convivência digna e democrática. Debatendo a problemática do idoso na comunidade ponta-grossense, voltava-se para propor novas vivências ao idoso frente a essa mesma comunidade.

Mais uma vez o número de participantes foi significativo, 150 pessoas. A instituição e comunidade, dessa maneira, pareciam responder positivamente a implantação da UATI.

O projeto para a implantação do referido curso já havia sido realizado, porém um problema assinalava: os professores convidados para trabalharem nas diferentes disciplinas se apresentavam receosos diante da faixa etária dos alunos. Pensando em superar e vencer esses receios, organizou-se um Curso para Capacitação de Pessoal para trabalhar com a Terceira Idade. Foram convidados os professores interessados em trabalhar com a pessoa idosa, como docentes, os colaboradores no curso que acenava a sua implantação a instituição no ano seguinte. Ao todo foram 43aricipantes no curso revestindo a sua realização de grande êxito.

A caminhada incansável continuava e a equipe envolvida na organização e planejamento final participava do I Encontro Nacional de Estudantes Universitários da Terceira Idade e I Fórum de Coordenadores de Ações Educativas para a Terceira idade, realizado em Florianópolis, no ano de 1991.

O sonho tornava-se realidade, depois de muito trabalho, êxitos e fracassos, foi criada a Universidade Aberta para a Terceira Idade - UATI.

Assim, após os trâmites burocráticos exigidos pela instituição, a UATI foi aprovada pelo Colegiado Setorial em 20/12/1991; homologado pelo Conselho de Ensino, Pesquisa e Extensão pelo Parecer 23/92 de 14/04/1992. O grande sucesso deste curso, levou a Universidade Estadual de Ponta Grossa a institucionalizá-lo em 1997, sob a Resolução C.A. número 56/97. Desde esta data a oferta deste programa sócio- educacional se tornou ininterrupta e sistemática.

A pretensão era desenvolver um trabalho interdisciplinar e interdepartamental voltado ao processo de valorização humana e social da pessoa idosa através da implantação da UATI, como projeto extensionista e de atualização cultural na UEPG. Ampliava-se assim, a ação educativa dessa universidade através da educação permanente oferecida aos idosos, tendo como prerrogativa a valorização deste segmento etário no meio social.

A Universidade Aberta para a Terceira Idade fundamenta-se na concepção de educação permanente, na modalidade de educação não formal, entendida como um processo que ocorre ao longo da vida e volta-se para a auto-realização do idoso.

A UATI, com uma carga horária de 240 horas, estrutura-se com abordagem mulltidisciplinar, analisa constantemente a problemática do idoso nos diversos aspectos; biopsicológicos, filosóficos, político, espiritual, religioso, econômico e sócio cultural. A UATI promove as relações intergeracionais, priorizando o processo de valorização humana e social da pessoa idosa, pela aquisição de conhecimentos e aprimoramento de habilidades oportunizadas em diferentes espaços educativos. Uma das preocupações é possibilitar uma 
melhoria na qualidade de vida, possibilitando a reconstrução de um idoso mais alegre, otimista, partícipe e inserido socialmente.

Ressalta-se que a Educação permanente é um conjunto de experiências educativas apresentando-se como hipótese para o futuro diante das mudanças sociais, econômicas, culturais que se apresentam à nossa sociedade, integrando os diferentes meios de instrução e formação. Constitui como uma necessidade de ampliar a participação dos indivíduos na vida social e cultural, visando a melhoria nas relações interpessoais, qualidade de vida, compreendendo o mundo e tendo esperança de futuro.

"A capacidade de aprendizagem na terceira idade ou quarta idade deve ser estimulada, respeitando o ritmo de cada um e a necessidade de aliar as atividades a tarefas significativas, criando um ambiente de apoio para avanços dos idosos" (GROPPO, PARK, 2009, p.211).

A UATI possui como objetivos:

- proporcionar uma melhor qualidade de vida, tornando-o mais ativo, alegre, participativo e integrado à sociedade;

- possibilitar a aquisição de conhecimentos e informações em diferentes áreas apoiada na educação permanente.

- possibilitar a elevação da auto estima dos idosos;

- ampliar o convívio social do idoso;

- possibilitar o desenvolvimento de potencialidades intelectuais e habilidades por parte do idoso;

- valorizar a pessoa do idoso proporcionando sua atualização cultural e aquisição de conhecimentos nos aspectos filosóficos, históricos, políticos, econômicos, biopsicológicos, gerontológicos e integração social;

- respeitar e valorizar experiências de vida pessoal e profissional, especialmente dos aposentados e donas de casa, contribuindo efetivamente como monitores nas ações comunitárias;

- possibilitar um convívio intergeracional;

- favorecer a implantação de leis para os idosos, na Região dos Campos Gerais, particularmente na cidade de Ponta Grossa;

- desenvolver a função universitária de ensino, pesquisa e extensão, voltada à atenção e à promoção humana, na fase do envelhecimento.

- proporcionar a articulação, organização dos idosos para maior visibilidade e participação social deste segmento na sociedade;

- favorecer o empoderamento do idoso através de espaços educativos.

Com a inserção do idoso na comunidade universitária, ocorre a integração entre gerações, estimulando reflexões e questionamentos sobre os diferentes aspectos que envolvem essa faixa etária, analisando preconceitos e discriminações que são cristalizados socialmente embora sem fundamentação científica.

A UATI é composta por disciplinas teóricas e práticas, totalizando 240 horas, ao longo de três semestres letivos, seguindo o calendário universitário.

O Curso estrutura-se em quatro grandes eixos articuladores, nos quais baseiam-se as disciplinas oferecidas, são eles: saúde, nutrição e qualidade de vida; cultura e arte; esporte e lazer; direito, empoderamento e cidadania.

As disciplinas teóricas abordam as diferentes dimensões humanas e sociais, apoiam-se nos eixos articuladores e são ministradas por diferentes profissionais em suas áreas específicas.

São também oferecidas as disciplinas optativas que atualmente são em número de treze. Estas disciplinas de caráter optativo possibilitam ao idoso experimentar diferentes 
áreas artísticas e de conhecimentos, muitas vezes despertando interesses e desenvolvendo habilidades que ele mesmo desconhecia possuir.

Entre essas disciplinas optativas estão as que se voltam para aquisição de conhecimentos e desenvolvimento intelectual como o inglês, o espanhol e informática. Entre as disciplinas que possibilitam o desenvolvimento de habilidades artísticas encontram-se a pintura em tela, o artesanato, a Seresta e o Teatro. As atividades físicas também são evidenciadas através das disciplinas de natação e hidroginástica, dança de salão, yoga, alongamento, relaxamento, caminhada e atividades esportivas.

O currículo da UATI é organizado de maneira interativa, conforme as opções dos próprios idosos, sendo as disciplinas teóricas de caráter obrigatório e as práticas de caráter optativo.

As disciplinas teóricas abordam as diferentes dimensões humanas e sociais, apresentadas por profissionais em suas áreas específicas de atuação, entre elas: sociologia, filosofia, psicologia, direito, previdência social, história, geografia, relações humanas, educação, esoterismo, política, economia, medicina, fisioterapia, odontologia, nutrição, jornalismo, turismo, educação física e meio ambiente.

As disciplinas práticas envolvem diferentes atividades, como: dança de salão, natação e hidroginástica, relaxamento e alongamento, atividades esportivas, yoga, caminhada, informática, espanhol, inglês, pintura em tela, artesanato, teatro e seresta.

As disciplinas teóricas formam o primeiro ano do curso e depois, no terceiro semestre letivo são substituídas pelo Estágio de Inserção Comunitária.

O Estágio realizado na UATI constitui o último semestre letivo do Curso, no qual são programadas atividades como visitas a diversas instituições, entre elas: casa asilares, creches, centros de convivência de idosos. São realizadas entrevistas para detectar as reais necessidades de cada local e depois são desenvolvidas atividades filantrópicas, assistenciais, recreativas, visando uma socialização e integração. Os projetos de inserção são elaborados pelos idosos, sob a orientação da professora da disciplina, e depois eles vão a campo implementar as atividades planejadas.

As atividades desenvolvidas atualmente assumem as características de Projetos e são as seguintes: Resgate Cultural de brincadeiras e cantigas, Memoria Cultural, Contador de histórias, Memorial e História de Vida.

Para maior entrosamento entre os 520 idosos que frequentam o Curso, existe o Grêmio da Universidade Aberta da Terceira idade (GUATI), com a atribuição de organizar festas temáticas e viagens culturais.

Para acompanhar e garantir o êxito do Curso são realizadas avaliações contínuas, pelos alunos, professores e coordenadora. As disciplinas da UATI são reformuladas conforme as necessidades e sugestões apresentadas. Os alunos recebem certificados de atualização.

Paralelamente é desenvolvido o Projeto de extensão Jornal da UATI, possibilitando a integração intergeracional. O Jornal elaborado por alunos de Jornalismo, juntamente com os idosos, apresenta notícias específicas selecionadas conforme o interesse dos idosos. Hoje registra-se o quinto ano do Jornal com edição trimestral.

\section{CONSIDERAÇÕES FINAIS}

Diferentes grupos se organizaram na busca de possibilitar um espaço educacional para os idosos em diferentes universidades brasileiras, hoje pode-se considerar que deixou de ser um sonho para estar materializado pela existência de mais ou menos 156 cursos/projetos para esta faixa etária. 
Não se pode estabelecer com precisão este número porque não existem registros e nenhuma pesquisa ainda foi realizada para quantificá-los. Entretanto, está sendo criada a Associação Brasileira de Universidades Abertas a Terceira Idade e pensa-se que, em pouco espaço de tempo, seja viabilizada esta informação.

A educação para o idoso já é reconhecida, embora a inclusão em políticas educacionais seja pequena, existem movimentos para que isto se torne possível. O Estatuto do Idoso, mesmo referenciando a relevância educativa para esta faixa etária, precisa avançar em práticas para ser realmente efetivado.

A educação assume função importante para auxiliar na superação de situações de vulnerabilidade com que se defrontam os idosos. O envelhecimento conduz a uma mudança significativa nos papéis sociais, que precisam de uma re-significação tanto em nível micro, a família, como em nível macro, a sociedade.

A educação é um meio de libertação, empoderamento do idsoso, através da aquisição de conhecimentos, atualização visando uma vida mais saudável, ativa e participativa e, por meio da integração social propiciar um crescimento pessoal e intelectual ao idoso, superando a conotação de educação como assistencialismo. O idoso quando instrumentalizado com conhecimentos, busca a superação de sua vulnerabilidade e dos desequilíbrios sociais, por meio de um novo desenho de paradigma de velhice. Tornase necessária a transformação progressiva do papel social do idoso, esboçando a possibilidade de reconhecimento como sujeito psíquico existente e como agente social, permitindo uma outra maneira de redimensionamento da inserção dos idosos na ordem da temporalidade, delineando a possibilidade de dimensão de futuro.

A reconstrução da trajetória da criação da UATI/UEPG permite uma maior visibilidade e divulgação da existência do espaço educacional para o idoso em uma universidade do interior do Paraná que hoje se constitui como um modelo pelo protagonismo, pioneirismo e dedicação, sendo o seu sucesso reconhecido em níveis nacional e internacional.

A educação ao longo da vida "deve fazer com que cada indivíduo saiba conduzir seu destino, num mundo onde a rapidez das mudanças se conjuga com o fenômeno da globalização para modificar a relação que homens e mulheres mantem com o espaço e o tempo" (DELORS, 2001, p. 105).

As Universidades Abertas para a Terceira idade apresentam-se como fortes aliadas na organização, articulação deste segmento populacional em favor das reivindicações de seus direitos, maior atenção e superação da vulnerabilidade e situações que envolvem violência e descaso a esta faixa etária.

Muitos desafios são delineados para as UATIs, entre os quais possibilitar ao idoso, pela educação, a participação, autonomia, não discriminação, atenção à diversidade, independência, cuidado/assistência, auto realização, dignidade e promoção de conhecimento, aspectos que estão prescritos na Política Nacional, Lei 8842/94 e no Estatuto do Idoso, Lei 10.741/03 .

Outro desafio que inquieta e traz novamente a discussão é a de integrar nos currículos dos diferentes cursos de graduação a disciplina que verse sobre o tema de envelhecimento e velhice, considerando a velhice como uma etapa da vida em que todos querem chegar, porém com qualidade e dignidade. Esta questão está prevista no Art. 22 do capítulo V do Estatuto do Idoso.

Não se pode deixar de registrar a preocupação com a qualificação de profissionais para trabalharem com o idoso a também o incremento de pesquisas sobre essa temática para fundamentarem uma prática mais eficiente. 
A preocupação primeira, reside na implementação e operacionalização, pelo governo e pela sociedade civil, de políticas públicas e educacionais com ações que minimizem a situação do idoso evitando um agravamento do panorama hoje pouco otimista.

Hoje esboça-se no Brasil um perfil diferenciado de idoso, mais ativo, participativo, valorizado, conhecedor de seus direitos e deveres como cidadão, contribuindo para o desenho de um novo paradigma de velhice do século XXI.

\section{REFERÊNCIAS}

BATISTA, A. S. et al. Envelhecimento e dependência: desafios para a organização da proteção social. Brasília: MPS, SPPS, 2008. Coleção Previdência Social, v. 28.

BRASIL. Lei $\mathbf{n}^{\mathbf{0}} \mathbf{8 8 4 2}$, de 4 de janeiro de 1994. Dispõe sobre a Política Nacional do Idoso. Brasília, 1994.

Lei $\mathbf{n}^{\circ} 10741$ de 3 de outubro de 2003. Dispõe sobre o Estatuto do Idoso.

Brasília, 2003.

BOTH, A. Envelhecimento humano: múltiplos olhares. Passo Fundo: UFPF, 2003.

CACHIONI, M. Envelhecimento bem sucedido e participação numa universidade para a terceira idade: a experiência dos alunos da Universidade São Francisco. Campinas, 1998 (Dissertação de Mestrado em Educação) - Faculdade de Educação da Unicamp.

Quem educa os idosos? Um estudo sobre professores de universidades da terceira idade. Campinas: Alínea, 2003.

CARVALHO,H.M. A Universidade Aberta à Maturidade. Revista Abceducatio ,37:2023,ago.2004.

CAMARANO, A. A; PASINATO, M. T. Envelhecimento, pobreza e proteção social na América Latina. Papeles de Población, abril-junho, n52, Universidad Autónoma Del Estado de México, Toluca, México, p. 9-45, 2007.

DELORS, J. et al. Educação um tesouro a descobrir. São Paulo: Cortez/Unesco, 2001.

FREIRE, P. Educação e Mudança. São Paulo: Paz e Terra, 1979.

GADOTTI, M. A educação contra a educação. Rio de Janeiro: Paz e Terra, 1984.

GATTI, D.JR. A história das Instituições educacionais.In: Novos temas em história da Educação Brasileira: instituições escolares e educação na imprensa.Campinas, São Paulo:Autores Associados. Uberlândia, MG:EDUFU,2002. 
GOHN, M.G. Educação não-formal na pedagogia social. Congresso Internacional de Pedagogia Social, 1, 2006, São Paulo, Anais do $1^{\mathbf{0}}$ Congresso Internacional de Pedagogia Social; Autores sociais. Petrópolis: Vozes, 2006

HERÉDIA, V. B. M. A família, a educação e o envelhecimento humano: desafios para a sociedade. In: CASARA, M. B.; CORTELLETTI, I. A.; BOTH, A. Educação e envelhecimento humano. Caxias do Sul: EDUCS, 2006. p. 109-132.

IBGE. Projeção da População por Sexo e Idade para o Período 1980 - 2050. Diretoria de Pesquisas. Coordenação de População e Indicadores Sociais. Revisão 2008, Rio de Janeiro: Fundação Instituto Brasileiro de Geografia e Estatística, 2008.

JORDÃO NETTO, A. Gerontologia básica. São Paulo: Lemos, 1997

LOPES, A. Os desafios da gerontologia no Brasil. Campinas: Alinea, 2000.

MOODY, H. R. The new aging enterprise. Occasional papers. Washington, Academic Affairs, n. 4, p. 1-50. may. 2008.

MOSQUERA, J. Vida adulta: personalidade e desenvolvimento. Porto Alegre: Sulina, 1975.

NERI, A. DEBERTY, G. Velhice e sociedade. Campinas: Papirus, 1999.

OLIVEIRA, R. C. S. Terceira Idade: do repensar dos limites aos sonhos possíveis.

Campinas: Papirus, 1999.

O processo histórico do estatuto do idoso e a inserção pedagógica na

universidade aberta. Revista HISTEDBR Online, Campinas, n. 28, p. 278-286, dez. 2007.

OLIVEIRA, R.C.S.; SCORTEGANA, P.A.; OLIVEIRA,F.S. O envelhecimento e a velhice: teorias, demografia e , política. Curitiba: CRV, 2011.

ONU. Indicadores demográficos populacionais. Revisão 2006.

ONU. Indicadores demográficos populacionais. Revisão 2008.

PACHECO, J.L. AS universidades abertas à terceira idade como espaço de convvência entre gerações. In: SIMSON, O.R.M.V.; NERI, A.L.; CACHIONI,M. (orgs). As múltiplas faces da velhice no Brasil. Campinas: Alínea, 2003.

PAIVA, V. Educação Permanente: ideologia educativa ou necessidade econômico-social? In: PAIVA, V.; RATTNER, H. Educação permanente e capitalismo tardio. São Paulo: Cortez, 1985. p. 7-63.

PALMA, L. Educação permanente e qualidade de vida. Passo Fundo: UPF, 2000.

PARK, M.B. e GROPPO, L.A. Educação e velhice. São Paulo: Setembro, 2009. 
PICONEZ, S. Educação escolar de jovens e adultos. São Paulo: Paulinas, 2002.

PINTO. Á.V. Sete lições de educação de adultos. São Paulo: Cortez, 1989.

SARAIVA, I. S. Educação de jovens e adultos: dialogando sobre aprender e ensinar. Passo Fundo: UPF, 2004.

SAVIANI, D. Fontes, História e Historiografia da Educação. Autores Associados, Curitiba,PR, 2004.

SILVA, R. Fundamentos teóricos e metodológicos da pedagogia social no Brasil. Congresso Internacional de Pedagogia Social, 1, 2006, São Paulo, Anais do $1^{\circ}$ Congresso Internacional de Pedagogia Social, USP, 2006.

TEODORO, M. UNATI/UERJ: uma proposta de educação permanente para o cidadão idoso. 2006. Dissertação (Mestrado em educação) - Universidade Católica de Petrópolis, Rio de Janeiro, 2006.

World Health Organization (WHO). Envelhecimento ativo: uma política de saúde. Brasília, Organização Pan-Americana da Saúde, 2005.

Notas

${ }^{1}$ Doutora em Educação. Professora do Mestrado e Doutorado em Educação na UEPG. Coordenadora da Universidade Aberta para a Terceira Idade na UEPG. Pesquisadora Bolsa Produtividade pelo CNPq. E-mail: soliveira13@uol.com.br

Recebido em: $\quad 24.04 .12$

Aprovado em: $\quad 30.05 .12$ 